\title{
Rare Congenital Diaphragmatic Defects
}

\author{
Man Mohan Harjai \\ Surgical Division Army Hospital (Research and Referral), New Delhi \\ India
}

\section{Introduction}

Congenital diaphragmatic hernia $(\mathrm{CDH})$ is a developmental defect of the diaphragm that allows abdominal viscera to herniate into the chest. The reported incidence of $\mathrm{CDH}$ is estimated to be between 1 in 2000 to 5000 births. Defects are more common on the left side, with approximately $80 \%$ being left sided and $20 \%$ right sided. Bilateral $\mathrm{CDH}$ defects are rare and have a high incidence of associated anomalies.

$\mathrm{CDH}$ is thought to represent a sporadic developmental anomaly, although a number of familial cases have been reported. The cause of a $\mathrm{CDH}$ is unknown. As with other embryopathies there is increasing evidence that $\mathrm{CDH}$ may be due to the exposure of genetically predisposed or susceptible individuals to environmental factors. The embryologic development of the diaphragm remains incompletely understood and involves multiple, complex cellular and tissue interactions. The fully developed diaphragm is derived from four distinct components: (a) the anterior central tendon forms from the septum transversum, (b) the dorsolateral portions form from the pleuroperitoneal membranes, (c) the dorsal crura evolve from the esophageal mesentery, and (d) the muscular portion of the diaphragm develops from the thoracic intercostal muscle groups. Failure of normal closure of the pleuroperitoneal canal in the developing embryo and delay or failure of muscular fusion results to development of diaphragmatic defect and herniation of abdominal contents. Abdominal contents herniate and compress the ipsilateral developing lung. The volume of herniated contents may be small or large enough to contain most of the gut, spleen, or liver. Because herniation occurs during a critical period of lung development when bronchial and pulmonary artery branching occurs, lung compression by the herniated bowel results in pulmonary hypoplasia. In addition, arterial branching is reduced and there is muscular hyperplasia of the pulmonary arterial tree, resulting in pulmonary hypertension.

Affected neonates usually present in the first few hours of life with respiratory distress that may be mild or so severe as to be incompatible with life. Infants with CDH most often develop respiratory distress in the first few hours or days of life. The spectrum of presentation can vary from acute, severe respiratory distress at birth, which is common, to minimal or no symptoms and they may present late which is less common (beyond the neonatal period) and represents true diagnostic challenge. Diagnosis of the defect is difficult. Symptoms are non-specific and can be misleading. 


\section{Types of diaphragmatic defects}

Various types of Diaphragmatic defects include (a) paravertebral type or posterolateral type (Bochdalek type) (80\%) (b) parasternal type (in the anterior foramen of Morgagni) (c) diaphragmatic eventration, (d) central diaphragmatic hernia (septum transversum) and (e) diaphragmatic agenesis (1/250 000 births). The central $\mathrm{CDH}$ occurs in the midline of the septum transversum and accounts for 1 to $2 \%$ of the total cases of $\mathrm{CDH}$.

\section{Anterior diaphragmatic hernia of Morgagni}

The anterior diaphragmatic hernia of Morgagni is located anteromedially on either side of the junction of the septum transversum and the thoracic wall. Morgagni hernia is a rare malformation ( $2-3 \%$ of diaphragmatic hernias). This hernia is usually asymptomatic in children. The rarity, as well as the vague and nonspecific presentations, contributes to the delay in diagnosis. Commonly, the presentation in the pediatric age group is that of recurrent chest infection and rarely with gastrointestinal symptoms. The variable clinical picture results in a considerable diagnostic challenge. Up to $5 \%$ of cases are incidentally identified in adults undergoing studies for other reasons. Physicians caring for these patients should be aware of this, and a high index of suspicion is recommended to obviate delay in diagnosis with its associated morbidity. Presentation of the Morgagni hernia with obstruction had been reported in adult but not in children (1). Diagnosis is usually by chest radiograph in 2 planes or CT scan. The optimal method of surgical repair is not known due to the rarity of this condition. The surgical approach may be either transabdominal or thoracic. The surgical repair is indicated even in asymptomatic patients. There are increasing reports about the role of minimally invasive approach. The recurrence is low with an excellent prognosis. (2). Morgagni hernia should be strongly considered in patients with Down's syndrome admitted repeatedly for chest infections. (3). Sternal clefts are rare chest wall anomalies which may occur in isolation or in association with cardiac, pericardial, and anterior diaphragmatic defects (4). The intrathoracic herniation of liver through Morgagni hernia may compressed the right chambers of the heart in a newborn causing cardiac compression (tamponade) resulting in a diagnostic dilemma (5). The autopsy findings in a newborn revealed multiple uncommon anomalies associated with diaphragmatic defects. The baby had bilateral diaphragmatic agenesis associated with right pulmonary hypoplasia, left pulmonary agenesis, multiple cardiac abnormalities and gallbladder agenesis, which is a very rare entity and incompatible with life (6).

\section{Congenital diaphragmatic eventration}

Congenital diaphragmatic eventration is defined as the abnormal elevation of the diaphragm and is characterized by muscular aplasia, resulting from impaired ingrowth of muscle fibres into the diaphragm during the first trimester. The abnormally elevated diaphragm may compress the ipsilateral lung, and with respiratory effort the mediastinum may shift towards the normal side. The congenital form may be indistinguishable from a diaphragmatic hernia with a sac, and symptoms are usually similar. Diagnosis is usually made on fluoroscopy or ultrasound examination of the chest. In such cases, the diaphragm moves paradoxically with respiratory motion. This paradoxic movement may be so marked that it results in severe compromise of gas exchange. A small eventration may be left 
untreated (7). Repair is indicated when a large functional deficit in the function of the ipsilateral lung on ventilation/perfusion studies is found in an apparently asymptomatic patient. In such cases, the compressed lung will not grow well. For the same reason, a large eventration should be repaired even when asymptomatic. If the defect is large, it may not be possible to repair it by direct approximation with nonabsorbable interrupted 2-0 sutures. The use of prerenal fascia, rib structures, the latissimus dorsi muscle, rotational muscle flaps from the thoraco-abdominal wall and prosthetic patches is recommended in difficult and wide gap hernias. Repair may be performed either through the abdomen or the chest either as an open procedure or laparoscopically.

Congenital anomalies in the position or attachment of proximal portion of alimentary tube occur as a part of general transposition of the viscera. Situs inversus totalis is a rare, congenital condition that is characterized by the development of the thoracic and abdominal viscera in a mirror image to their normal orientation but isolated dextrogastria is the rarest of all visceral transpositions. Isolated dextrogastria is a very rare congenital anomaly in which the stomach is right-sided while the intestines, the organs in the chest, and the other organs in the abdomen are in normal situs. This rare anomaly can coexists with eventration of the right hemidiaphragm, creating further confusion. These rare combinations often present difficulties in diagnosis which may lead to inappropriate treatment. It may simulate abscess, right-sided hiatal hernia, pleural effusion, pneumonia or other pathology at the right base. The importance of recognising the spectrum of situs anomalies is because the altered anatomy associated with these anomalies may result in misdiagnosis. At times it is difficult to distinguish preoperatively between eventration of diaphragm and congenital diaphragmatic hernia with a sac in a newborn [8].

The association of isolated asymptomatic dextrogastria (Fig 1,2) with eventration of the right hemidiaphragm creates a diagnostic dilemma, delay in diagnosis and management in such cases (9). Evaluation with contrast in such cases is often suboptimal and MRI may help in these neonates and infants depicting the anomaly without radiation risk to the child [10]. Gastric volvulus of the right sided stomach in an infant with eventration of right hemidiaphragm associated with malrotation is reported in the literature with its diagnostic dilemmas [11]. The diagnostic uncertainty could only be solved at laparotomy in such cases. However, this clinical entity should be taken into account in the differential diagnosis of children with respiratory distress and GI disturbances.

\section{Congenital diaphragmatic hernia}

The late presentation of the congenital diaphragmatic hernia $(\mathrm{CDH})$ with subtle symptoms of recurrent colicky pain abdomen or respiratory distress are sometime misleading and the first requisite for the diagnosis of a congenital diaphragmatic hernia (CDH) in late presenters is a high index of suspicion. These types of cases require evaluation with X-Ray Chest, contrast study of gut and if required CT scan of chest. (Fig 3 to 9). The lack of typical clinical presentation in cases of late presenting $\mathrm{CDH}$ leads to delayed diagnosis of the defect (12). Cystic lesions or masses in the lower lung fields should suggest the possibility of a $\mathrm{CDH}$ with herniated abdominal content at any age.

Congenital diaphragmatic hernias should be included in the differential diagnosis of apparent lower lobe pneumonias in all children below a month of age (13). In a series of 12 


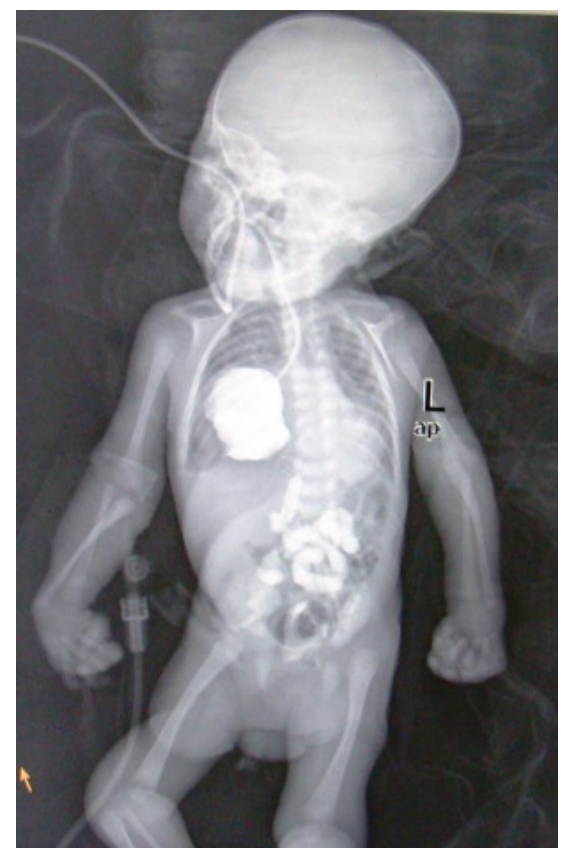

Fig. 1 Contrast radiograph showing stomach lying on the right side of chest while all other viscera's are normally placed in a case of right eventration of diaphragm with isolated dextrogastria.

patients of delayed presentation of $\mathrm{CDH}$, authors found that most of the patients presented with recurrent chest infections (14). However in another observation the authors noticed that the gastrointestinal problems were more common in left-sided hernias, whereas respiratory symptoms predominated in right-sided lesions in late-onset $\mathrm{CDH}$ (15). The authors from Egypt concluded that the late-presenting $\mathrm{CDH}$ should be included in the differential diagnosis of any child with recurrent non specific respiratory or gastrointestinal symptoms associated with an abnormal chest X-ray film and GI contrast studies should be a part of the diagnostic work-up of these patients $(16.17,18,19,20)$ ). However, when a diagnosis of $\mathrm{CDH}$ has been established, albeit asymptomatic, it must be promptly treated surgically in order to prevent complications, such as strangulation or bowel perforation, and thus avert a potentially fatal outcome. The endoscopic approach of late-presenting Morgagni and Bochdalek $\mathrm{CDH}$ is also a safe alternative in expert hands (21). In an interesting case report of right-sided Bochdalek hernia with a right intrathoracic stomach and organo-axial torsion which was misdiagnosed initially, and was treated as a case of hyperactive airway disease. The child was operated by right thoracotomy, excision of the hernia sac that contained the stomach, greater omentum and part of the liver was done and reduction of the viscera into the abdominal cavity with simple closure of the diaphragmatic defect was carried out (22). Thus the late presentation has been associated with varied manifestations, hence proper clinical evaluation, a high index of suspicion and adequate management, which includes imaging and surgery after stabilization, gives excellent results in such cases. 


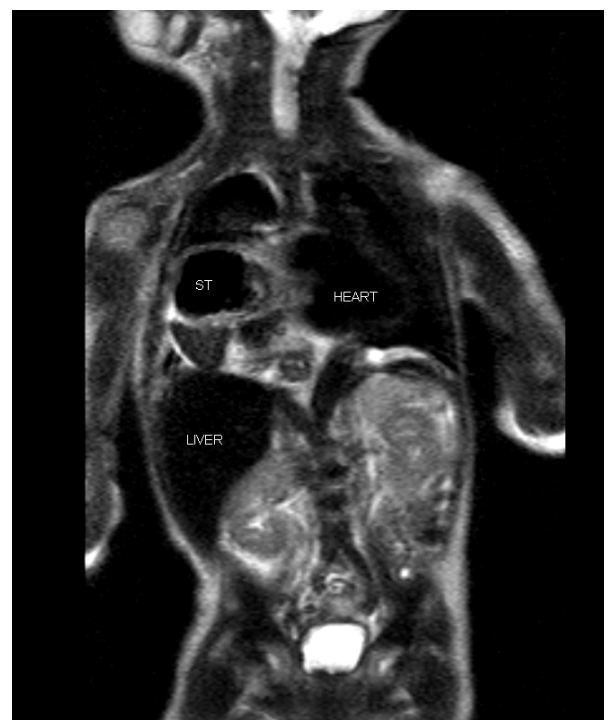

Fig. 2 MRI reconstruction of newborn revealed stomach (ST) lying on the right side of chest above the liver while all other viscera's are normally placed.

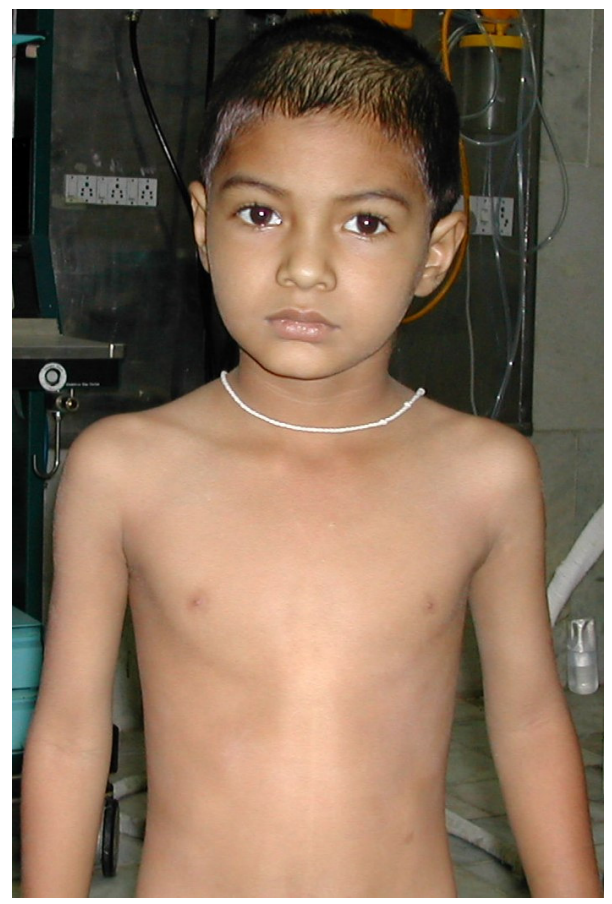

Fig. 3. Clinical photograph of the 7 year old male boy presented with history of recurrent colicky pain abdomen and respiratory distress. 
The rare cases of unilateral diaphragmatic defects (agenesis) are also reported in the literature, which may remain undetected till adult life (23). Even in a rare combination the right congenital diaphragmatic hernia and an anorectal malformation coexisted in a neonate (24). A combination of two rare birth defects i.e. oculocutaneous albinism and a right-sided congenital diaphragmatic hernia was reported in a male Asian baby in the literature (25). A rare case of left pulmonary agenesis associated with congenital diaphragmatic hernia and congenital heart disease in a 2-year-old child with pulmonary hypertension is described in the literature (26). In 3 neonates complete absence of pericardium and ectopic liver has been described associated with congenital diaphragmatic hernia (27).

There are various atypical anomalies associated with Morgagni diaphragmatic defects presenting late, with less than 300 adult cases reported in the literature. In a 90-year-old woman, during her evaluation for a lung mass, the herniation of the liver through the foramen of Morgagni was detected on PET/CT scan (28). In a rare association Niramis R et al reported a 2-year-and-2-month-old boy with Down syndrome who had bilateral Morgagni and left Bochdalek hernias with hernial sacs in all of the diaphragmatic defects (29).
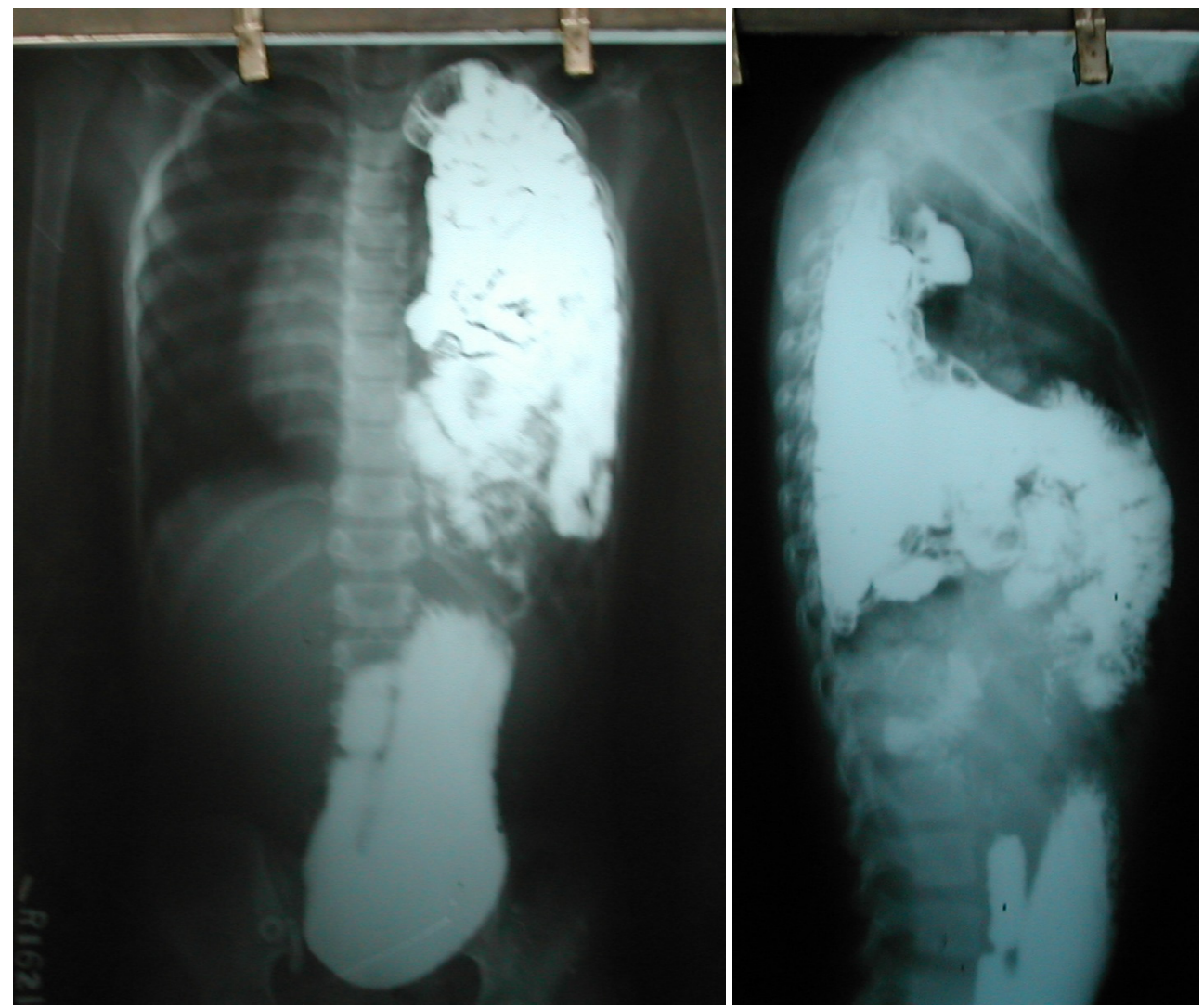

Fig. 4. Contrast study in 7 year old male boy who presented late, showing all his abdominal contents lying in the left chest except left colon. 


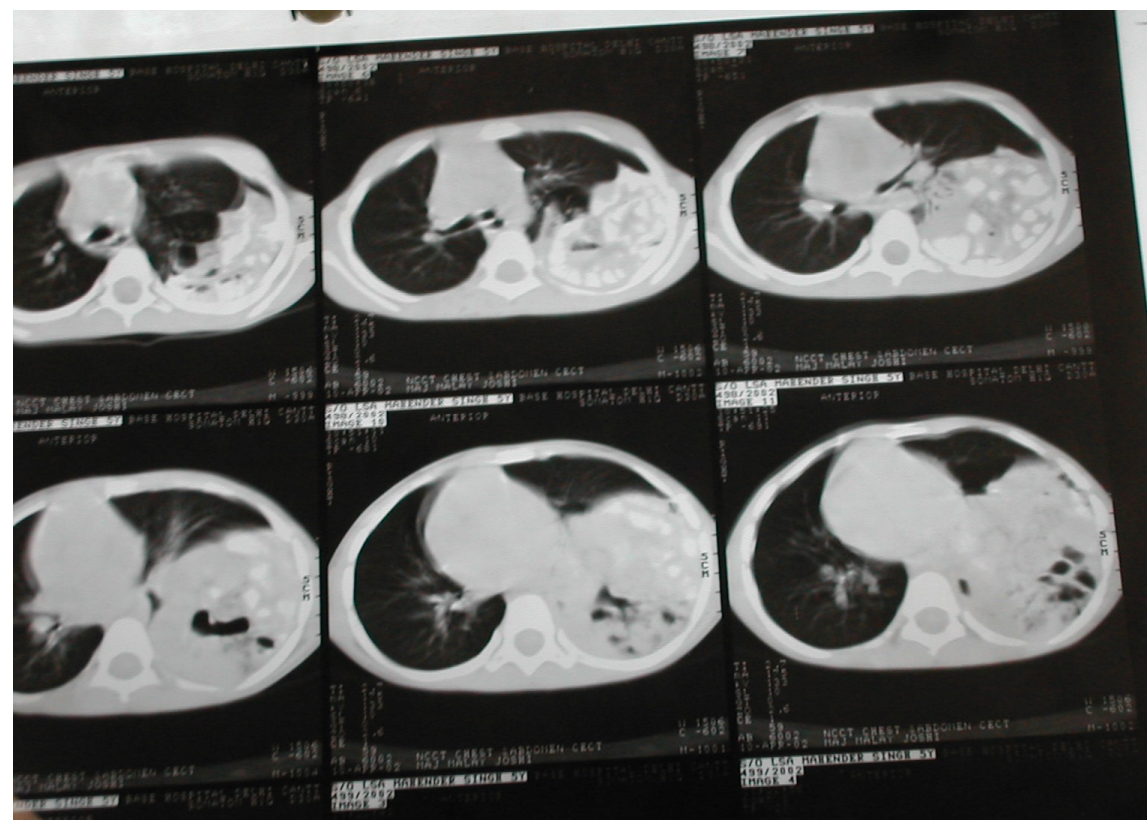

Fig. 5. CT scan of chest showing gut contents in the left chest.

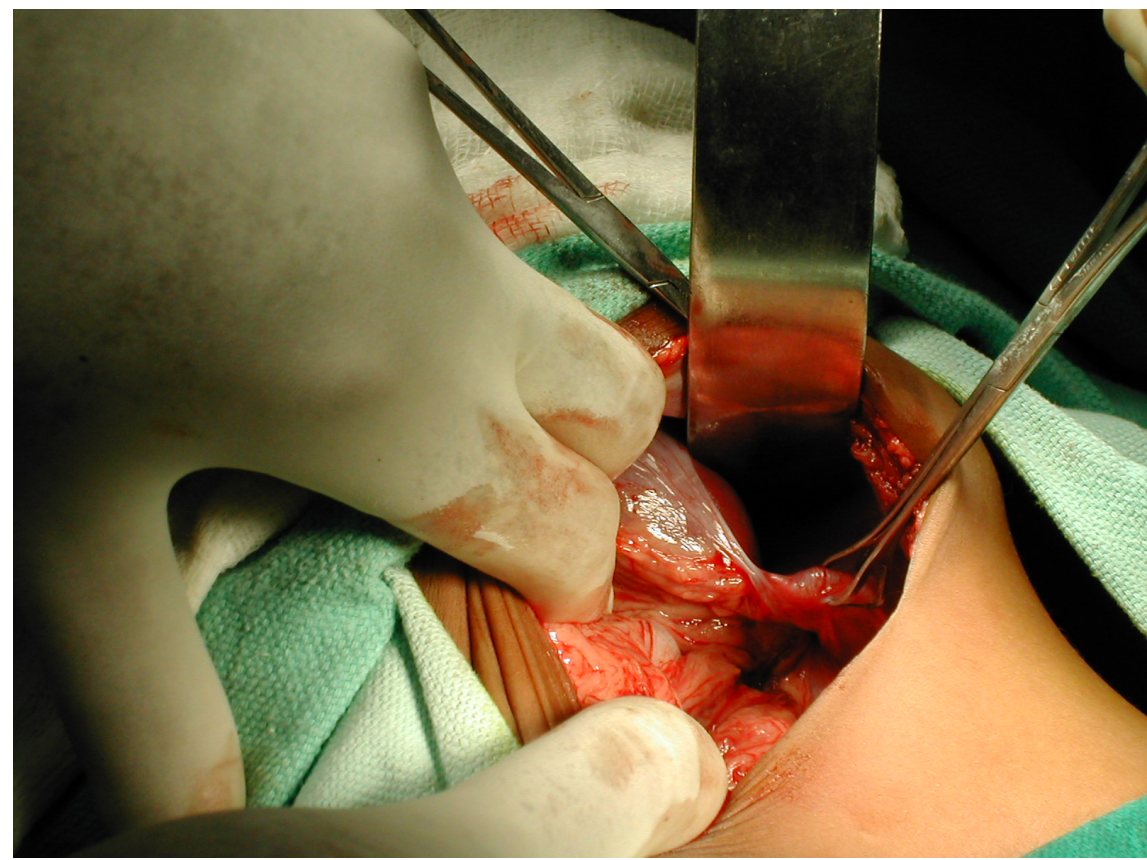




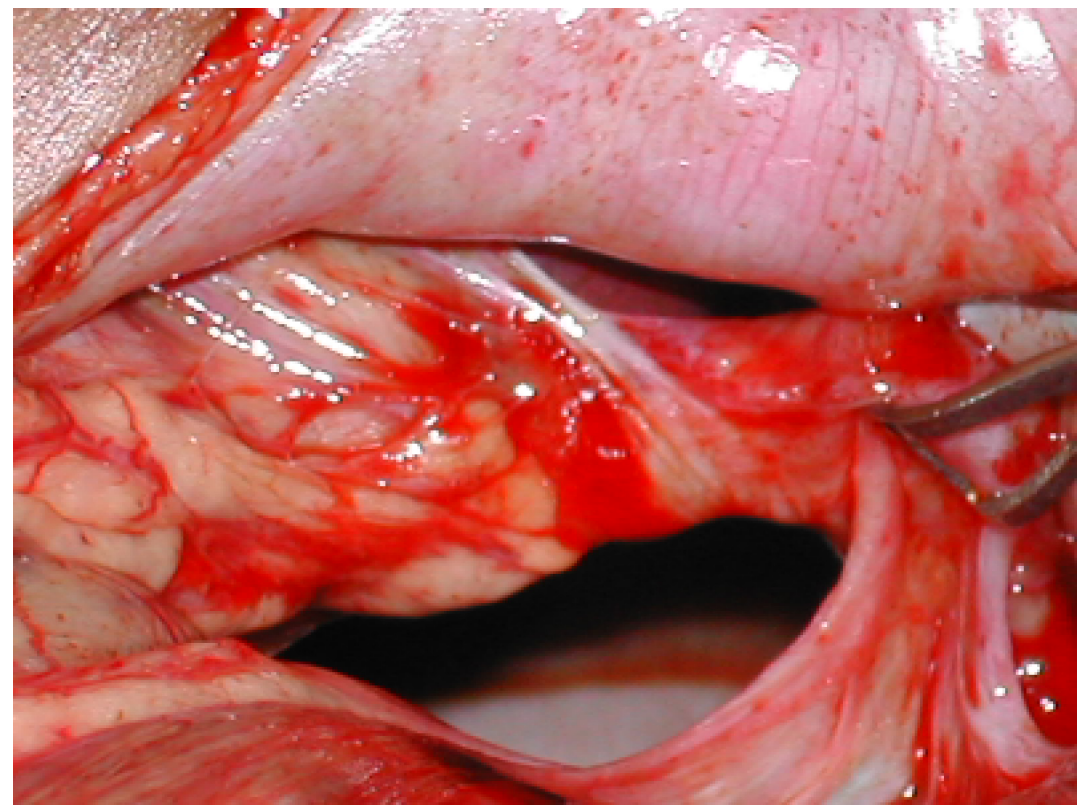

Fig. 6. Operative photographs showing diaphragmatic defect on the left side in the same boy who presented late at age of 7 year.

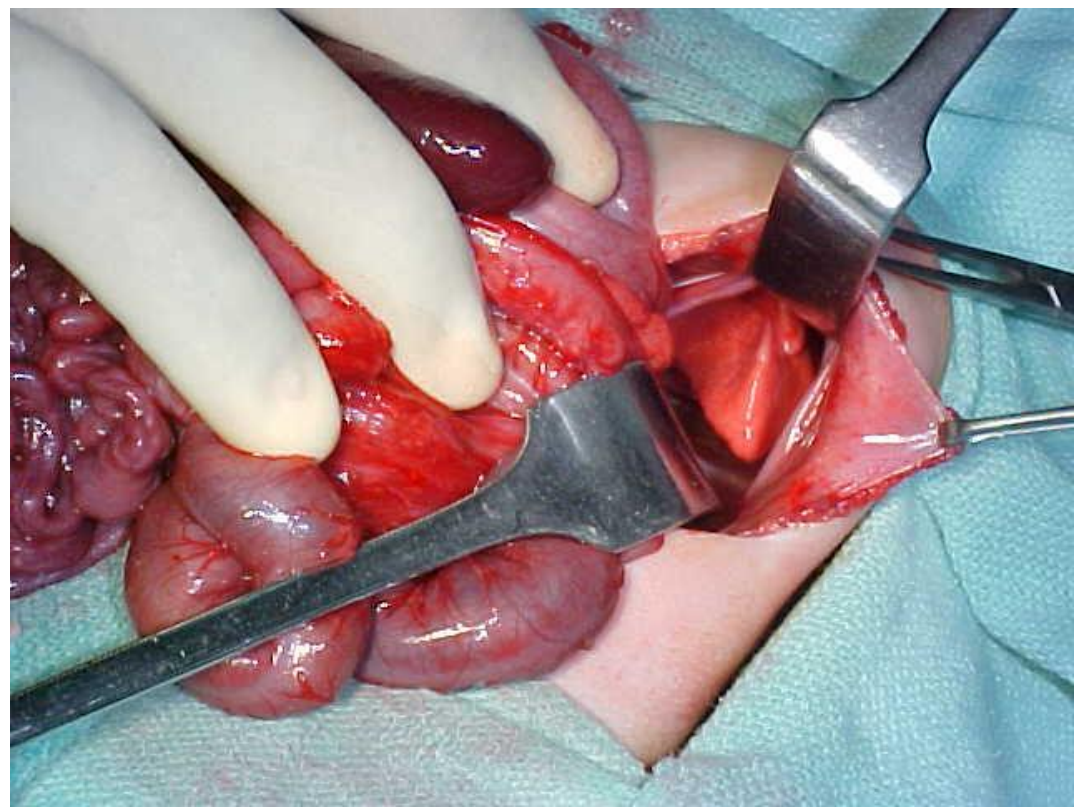

Fig. 7. Operative photograph of a case of Congenital Diaphragmatic Hernia, showing reduced contents and a small hypoplastic lung peeping through defect. 

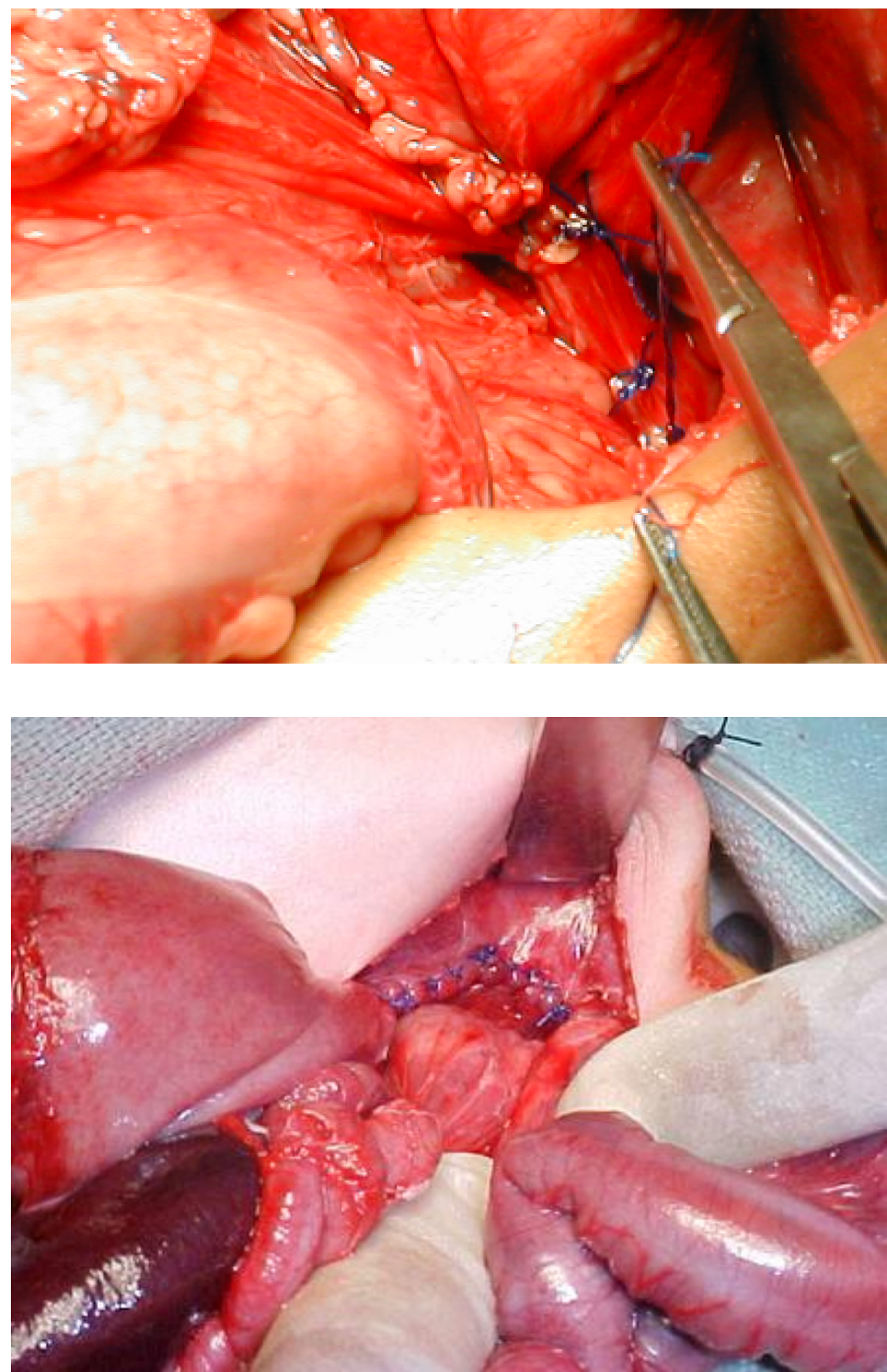

Fig. 8. Operative photographs showing completed repair of the defects on left side. 


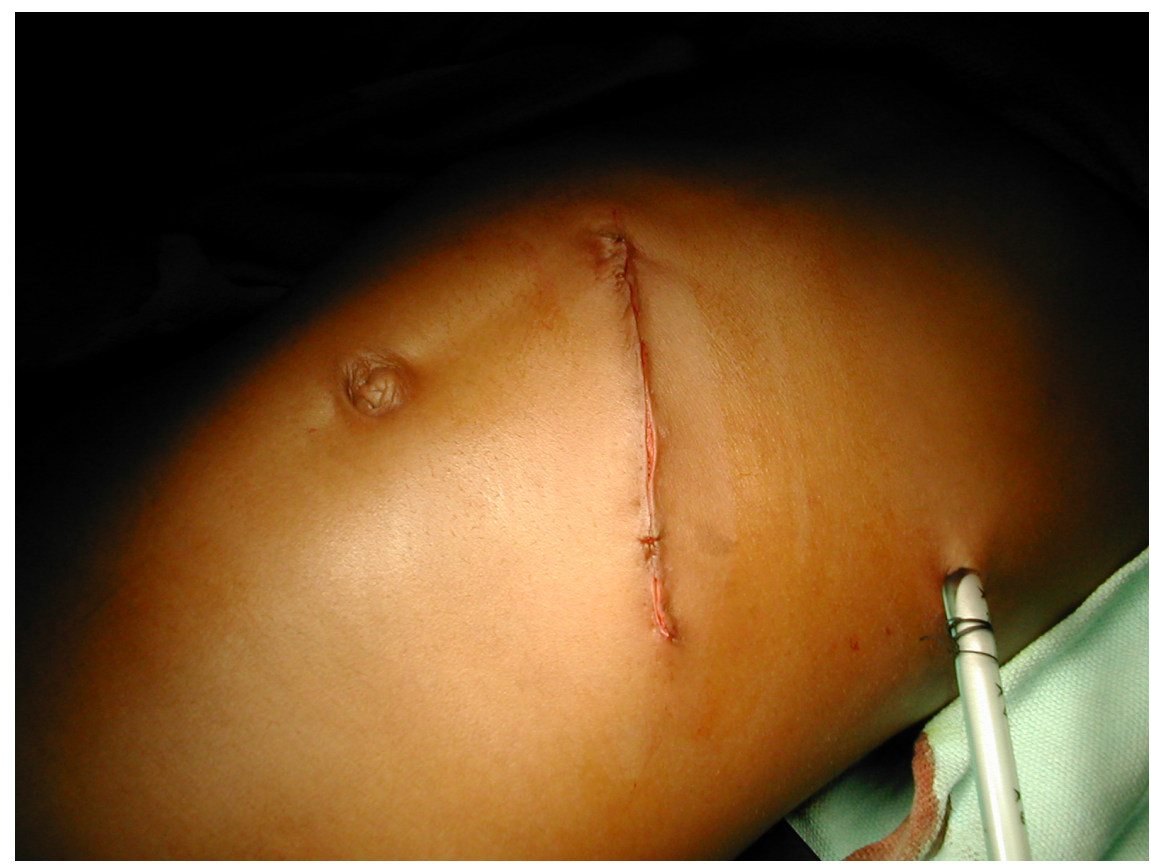

Fig. 9. Final photograph after repair of $\mathrm{CDH}$ in a boy who presented late, showing abdominal distension due to filling of abdominal cavity by contents from the chest cavity.

\section{Summary}

The rare congenital diaphragmatic defects are always posing a diagnostic challenge and require a very high index of clinical suspicion. Symptoms are always non-specific and can be misleading. The diagnosis of these defects is problematical. The rarity, as well as the vague and nonspecific presentations, contributes to the delay in diagnosis. At times the diagnostic uncertainty could only be solved at laparotomy in such cases. All such cases can be managed with open or minimal invasive surgery, once optimally stabilized. The outcome in such cases always depends on the presence or absence of associated other congenital anomalies.

\section{References}

Gangopadhyay AN, Upadhyaya VD, Gupta DK, Sharma SP. Obstructed Morgagni's hernia. Indian J Pediatr. 2007; 74: 1109-10

Nasr A, Fecteau A. Foramen of Morgagni hernia: presentation and treatment. Thorac Surg Clin. 2009; 19: 463-8.

Jetley NK, Al-Assiri AH, Al-Helal AS, Al-Bin Ali AM. Down's syndrome as a factor in the diagnosis, management, and outcome in patients of Morgagni hernia. J Pediatr Surg. 2011 46: 636-9. 
Slone T, Emil S, Meissner N, Behjatnia B, Fairbanks T, Romansky S. Sternal cleft, Morgagni hernia, and ectopic liver: a unique chest wall anomaly. J Pediatr Surg. 2007; 42: 2132-5.

S Breinig, Paranon S, Le Mandat A, Galinier P, Dulac Y, Acar P. Morgagni hernia causing cardiac tamponade. Arch Pediatr. 2010; 17:1465-8.

Karadeniz L, Guven S, Atay E, Ovali F, Celayir A. Bilateral diaphragmatic defect and associated multiple anomalies. J Chin Med Assoc. 2009; 72:163-5.

Sandstrom CK, Stern EJ. Diaphragmatic hernias: a spectrum of radiographic appearances. Curr Probl Diagn Radiol. 2011; 40: 95-115.

Rais-Bahrami K, Gilbert JC, Hartman GE, Chandra RS, Short BL. Right diaphragmatic eventration simulating a congenital diaphragmatic hernia. Am J Perinatol. 1996; 13: 241-3.

Harjai MM, Indrajit IK, Kansra M. Isolated dextrogastria simulating congenital diaphragmatic hernia: a diagnostic dilemma. Asian J Surg. 2010; 33: 59-62.

Aga P, Parashari UC, Parihar A, Singh R, Kohli N. MRI in isolated dextrogastria with eventration of the right hemidiaphragm with associated mesentero-axial volvulus. Pediatr Radiol. 2010; 40: 1576-8.

Nagdeve NG, Sarin YK. Volvulus complicating dextrogastria in an infant. Indian Pediatr. 2007; 44: 142-4.

Chang SW, Lee HC, Yeung CY, Chan WT, Hsu CH, Kao HA, Hung HY, Chang JH, Sheu JC, Wang NL. A twenty-year review of early and late-presenting congenital Bochdalek diaphragmatic hernia: are they different clinical spectra? Pediatr Neonatol. 2010; 51: 26-30.

Delport SD. Aftermath of failed diagnosis of late-presenting congenital diaphragmatic hernias. S Afr J Surg. 1996; 34: 69-72.

Numanoglu A, Steiner Z, Millar A, Cywes S. Delayed presentation of congenital diaphragmatic hernia. S Afr J Surg. 199; 35: 74-6.

Kitano Y, Lally KP, Lally PA. Congenital Diaphragmatic Hernia Study Group. Latepresenting congenital diaphragmatic hernia. J Pediatr Surg. 2005; 40:1839-43.

Elhalaby EA, Abo Sikeena MH. Delayed presentation of congenital diaphragmatic hernia. Pediatr Surg Int. 2002; 18: 480-5.

Zaleska-Dorobisz U, Bagłaj M, Sokołowska B, Ładogórska J, Moroń K. Late presenting diaphragmatic hernia: clinical and diagnostic aspects. Med Sci Monit. 2007; 13:137-46.

Cigdem MK, Onen A, Otcu S, Okur H. Late presentation of bochdalek-type congenital diaphragmatic hernia in children: a 23-year experience at a single center. Surg Today. 2007; 37: 642-5.

Pandey A, Tandon RK, Kureel SN, Wakhlu A, Rawat J. Evaluation of congenital diaphragmatic hernia in a tertiary health center of a developing country: management and survival. Hernia. 2008; 12:189-92.

Koziarkiewicz M, Piaseczna-Piotrowska A. Late manifestation of congenital diaphragmatic hernia - case report. Med Wieku Rozwoj. 2011; 15:106-9.

Marhuenda C, Guillén G, Sánchez B, Urbistondo A, Barceló C. Endoscopic repair of latepresenting Morgagni and Bochdalek hernia in children: case report and review of the literature. J Laparoendosc Adv Surg Tech A. 2009; 19: S95-101. 
Al-Shehri MA, Al-Binali AM, Eid WA, Osinowo OA, Mohammed NE. Late presentation of a right Bochdalek hernia with a right intrathoracic stomach and organo-axial torsion. Saudi Med J. 2005l; 26:1122-6.

Pousios D, Panagiotopoulos N, Argyriou P, Piyis A. Diagnosis and surgical management of diaphragmatic agenesis in an adult: Report of a case. Surg Today. 2010; 40: 357-9.

Raut A, Jadhav S, Vora R, Mandke J, Sarode V, Kittur D. Right congenital diaphragmatic hernia associated with anorectal malformation. J Pediatr Surg. 2010; 45: E25-7.

Hussain N, Dawrant MJ, Firmin RK. A unique case of a congenital diaphragmatic hernia in a boy with albinism. J Pediatr Surg. 2009; 44: e21-2.

Palma G, Giordano R, Russolillo V, Vosa C. Cardiac defect with diaphragmatic hernia and left lung agenesis--heart disease and other anomalies. Thorac Cardiovasc Surg. 2010; 58: 439-40.

Kamath GS, Borkar S, Chauhan A, Chidanand B, Kashyap N, Warrier R. A rare case of congenital diaphragmatic hernia with ectopic liver and absent pericardium. Ann Thorac Surg. 2010; 89: 36-7.

Makis W, Rush C. Liver herniation through the foramen of Morgagni: a pitfall in oncologic F-18 FDG PET/CT evaluation of the anterior mediastinum. Clin Nucl Med. 2011; 36: 491-3.

Niramis R, Poocharoen W, Watanatittan S.Bilateral Morgagni hernias association with left Bochdalek diaphragmatic hernia: a very rare anomaly. J Med Assoc Thai. 2008; 91: S157-60. 
(C) 2012 The Author(s). Licensee IntechOpen. This is an open access article distributed under the terms of the Creative Commons Attribution 3.0 License, which permits unrestricted use, distribution, and reproduction in any medium, provided the original work is properly cited. 